$\begin{array}{llll}\text { Submission: 26/07/2020; } & 1^{\text {st }} \text { round notif.: 13/10/2020; } & \text { New version: 24/10/2020; } & 2^{\text {nd }} \text { round notif.: 09/11/2020; } \\ \text { Camera ready: 12/11/2020; } & \text { Edition review: 11/12/2020; } & \text { Available online: 14/12/2020; }\end{array}$

\title{
Mediações-lives e Aprendizagens Etnocenológicas por Jovens com os Dispositivos Digitais, durante a Pandemia da Covid-19
}

\section{Title: Mediation-lives and Ethnocenological Learning by Young People with Digital Devices, during the Covid-19 Pandemic}

\author{
Vinicius Silva Santos \\ Universidade do Estado da Bahia - UNEB \\ vinnymil@yahoo.com.br
}

\author{
Henrique Nou Schneider \\ Universidade Federal de Sergipe - UFS \\ hns@terra.com.br
}

\begin{abstract}
Resumo
Este artigo tem como objetivo refletir sobre a emergência e exponenciação das performances "mediações-lives" criadas por jovens nas redes sociais digitais, durante a pandemia da COVID-19 e como estas experiências comunicacionais refletem, como achados potenciais e propositivos, para entender o campo das "aprendizagens etnocenológicas" com o uso dos dispositivos digitais. O estudo faz parte da investigação em andamento no Programa Pós-graduação em Educação da Universidade Federal de Sergipe - UFS, sendo uma pesquisa inspirada na multirreferencialidade, contando com a participação de dez jovens sergipanos, atores e atrizes sociais, engajados com coletivos Net-ativista (presenciais e virtuais), que criam estilizações performáticas (extraordinárias) de partilha, engajamento, mediação propositiva nas redes compostas por pares que, compreende o fenômeno da etcnocenolgia virtual da aprendizagem virtual juvenil na contemporaneidade.
\end{abstract}

Palavras-Chave: Mediações-lives; Aprendizagens Etnocenológicas; Jovens Contemporâneos; Dispositivos Digitais.

\begin{abstract}
This article aims to reflect on the emergence and exponentiation of the "mediation-lives" performances created by young people on digital social networks, during the COVID-19 pandemic and how these communicational experiences reflect, as potential and propositional, findings to understand the field of "ethnocenological learning" with the use of digital devices. This study is part of the ongoing investigation in the Graduate Program in Education at the Federal University of Sergipe - UFS, being a research inspired by multirreferentiality, with the participation of ten young people from sergipanos, social actors and actresses engaged with Net-activist collectives (face-to-face and virtual), which create (extraordinary) performance stylizations of sharing, engagement, purposeful mediation in networks composed by peers who understand the phenomenon of the of the virtual etcnocenolgia of youth virtual learning in contemporary times.
\end{abstract}

Keywords: Mediations-lives; Ethnocenological Learning; Contemporary Youth; Digital Devices.

Cite as: Santos, V. S. \& Schneider, H. N. (2020). Mediation-lives and Ethnocenological Learning by Young People with Digital Devices, during the Covid-19 Pandemic (Mediações-lives e Aprendizagens Etnocenológicas por Jovens com os Dispositivos Digitais, durante a Pandemia da Covid-19). Brazilian Journal of Computers in Education (Revista Brasileira de Informática na Educação - RBIE), 28, 892-908. DOI: 10.5753/RBIE.2020.28.0.892 


\section{Introdução}

Vivemos nesse limiar a exponenciação das experiências de interação entre os atores/atrizes sociais ${ }^{1}$ por meios dos dispositivos digitais de comunicação, com destaque para as diferentes ambiências $^{2}$ de imersão, a exemplo dos aplicativos de videotransmissão que passaram a fazer parte, com maior frequência, das ações humanas em tempos de isolamento social. Certamente, a deflagração pela Organização Mundial de Saúde - OMS, da epidemia mundial relacionada à COVID-19 e as consequentes medidas de afastamento ou isolamento social, adotadas pelos distintos países, estados e municípios obrigou, mesmo aqueles mais céticos, a repensar, organizar e experimentar formas de comunicação utilizando as Tecnologias Digitais de Informação e Comunicação - TDIC, especialmente os dispositivos digitais e seus serviços de comunicação, não só para atenuar os efeitos do distanciamento de seus familiares, mas também como maneira de continuar a exercer atividades socioculturais cotidianas, entre elas às demandas acadêmicas, escolares, etc.

Não obstante, panorama de paralisação das atividades coletivas presenciais tem favorecido o surgimento de diferentes experiências e ações por parte dos professores, alunos, estudiosos, famosos ou não. É importante ressaltar que antes desse cenário social, já existiam inúmeras e exitosas experiências com uso dos dispositivos digitais. Entretanto, chama atenção nesse contexto, a exploração dos dispositivos digitais e serviços de videotransmissão com diversas finalidades.

Pode-se destacar que os/as jovens partilham, criam e experimentam um variado conjunto de performances (presenciais e virtuais) convivendo e interagindo nos coletivos de interação. As atividades organizadas por esses atores sociais ocorriam nas redes sociais digitais e nas experiências de intervenção na comunidade local, antes da pandemia de COVID-19. Cabe ainda mencionar que, o estudo sobre as mediações dos jovens com os dispositivos digitais e suas performances emergem de um fazer implicado com o cotidiano das ações de intervenção. Não obstante, as lives protagonizadas por eles/elas, durante o isolamento social, tornaram-se uma potencial alternativa de comunicação, interação e produção de conhecimento em rede, frente ao isolamento social necessário.

Confome destacam Santaella (2017), Di Felice (2017) e Santos (2018) a exploração dos dispositivos digitais de comunicação acentuou os fenômenos ligados às experiências de comunicação convergentes, síncronas, ubíquas em cenários de hipermobilidade, suscitando outras formas de compartilhamento de informações, interações em ambiências de convívio, inclusive no campo das experiências de aprendizagens entre os atores/atrizes sociais nesse limiar.

Oportunamente, a utilização destes dispositivos, criou um "cosmos" medida potencial, fazendo surgir diferentes medições humanas com os saberes e conhecimentos entre pares online. Num espaço muito curto de tempo, notamos uma aproximação, por necessidade, dessas narrativas digitais, exigindo adaptação (em processo), com todos os seus percalços, no caso brasileiro, agravada por distorções socioeconômicas. É possível afirmar que estamos todos passando por um processo transitório de atualização das experiências coletivas de aprendizagens socioculturais, sendo estas imprescindíveis, com marcações únicas e projeções por revelar.

Nesse sentido, o principal objetivo desse trabalho é apresentar elementos conceituais e analíticos que corroboram para o entendimento desses fenômenos humanos, tomando-os como análise, as experiências criadas pelos jovens utilizando as redes de interação social, com destaque para o uso do Instagram. Tais observações permitem descrever cenários e projeções para o campo

\footnotetext{
${ }^{1}$ No trabalho, usamos a expressão "atores/atrizes sociais" baseado em Garfinkel (1967) para delimitar a natureza singular, múltipla e implicada dos jovens contemporâneos em suas performances e cenários de convívio.

2 Termo utilizado por Michel Maffesoli (2010) para se referir aos ambientes de interação e agregação entre os atores/atrizes sociais, a exemplo dos espaços-tempos de comunicação digital, possíveis no ciberespaço.
} 
da educacional, ao nosso ver, mais que nunca vivida e cultivada nas experiências espetaculares de imersão online, desterritorializadas, múltiplas e coletivas, a exemplo do que chamamos de mediações-lives e aprendizagens etnocenológicas, por meio de lives criadas por jovens nas redes, cujos sentidos revelam a emergência de outras lógicas de formação, cultivo e exploração de diferentes características performáticas constituintes das aprendizagens na contemporaneidade.

Este trabalho faz parte da pesquisa de doutorado, em andamento, no Programa de PósGraduação em Educação - PPGED da Universidade Federal de Sergipe - UFS, intitulada: Etnocenologia Virtual da Aprendizagem Juvenil Contemporânea: performances, experiências e mediações com dispositivos das culturas digitais. Nesse estudo, busca-se compreender como as narrativas juvenis em redes (online e presenciais) mediadas com os dispositivos digitais fazem surgir performances etnocenológicas, de comunicação, partilha, convívio, engajamento e solidariedade e como ocorrem os processos de aprendizagens etnocenológicas dos jovens com os dispositivos digitais nos coletivos comunitários (em redes virtuais e presenciais) de engajamento, ação comunicativa e solidariedade Net-ativistas. Atualmente o trabalho encontra-se e fase de transcrição e análise dos dados produzido durante a etapa de produção de dados.

\section{Caminhos e Percursos Metodológicos}

Este estudo se inspira na abordagem qualitativa de pesquisa, de cunho multirreferencial em função do objeto e dos caminhos que serão percorridos durante a aproximação com os participantes do estudo, estando inspirada na pesquisa etnográfica crítica de Macedo $(2010,2012,2015)$ que exige do pesquisador uma densa descrição das narrativas e fenômenos estudados. A esse despeito, Galeffi (2009) destaca os estudos qualitativos como sendo parte de uma possibilidade epistemológica que se organizada a partir das experiências humanas que se dão numa dinâmica complexa e na complementariedade de fatores que norteiam a construção do conhecimento.

Logo, esse estudo tem como inspiração a busca por uma pesquisa multirreferencial, capaz de priorizar um outro rigor investigativo. Seu interstício tem como fundamento a postura implicada do pesquisador que se permite conviver, partilhar, dialogar e tecer conhecimentos em busca de compreender os fenômenos da vida social. Segundo Macedo (2009) se trata de uma política de sentido no campo da pesquisa, baseada numa ética e rigor qualitativo que se opõe aos valores formais de rigor e neutralidade da pesquisa tradicional. Sendo assim, nessa caracterização de pesquisa, o pesquisador é ator social envolvido, não sendo possível vislumbrar as relações entre sujeito-objeto-pesquisador fora de marcadores analíticos complexos e, ao mesmo tempo, compreensivos.

Nesse sentido, se destaca como método de pesquisa a ser utilizado nesse estudo o método da etnopesquisa crítica definida por Macedo (2010) como sendo uma forma radical de re-existir a produção do conhecimento em educação. Nesse tocante, a etnopesquisa tem como interesse compreender as ordens socioculturais organizadas pelos atores sociais de modo a revelar os elementos intersubjetivos através da descrição dos fenômenos.

Os atores/atrizes sociais envolvidos nesse estudo são 10 jovens com idade entre 18 e 29 anos. A delimitação desse grupo levou em consideração a faixa-etária estipulada pela Lei 12.852/2018 que instituiu o Estatuto da Juventude no Brasil. A escolha desses atores sociais juvenis, observou os seguintes critérios: engajamento e atuação em coletivos juvenis de net-ativismo situados no Estado de Sergipe, utilização dos dispositivos digitais para imergir, interagir e mediar aprendizagens socioculturais em rede, participação nas culturas digitais por meio de ambiências coletivas de solidariedade (virtuais e presenciais), criação e atuação em performances estéticas, corporais e lúdicas ligadas aos jovens.

Os principais dispositivos utilizados para produção de dados durante o estudo foram: diário de itinerância (Evernote), memorial narrativo, entrevistas livres ou não-estruturadas, narrativas digitais e filmagem etnográfica. Para produção desse artigo foi priorizado a análise das narrativas 
digitais e imagéticas criadas pelos jovens durante o período da pandemia de COVID-19, uma vez que estas se apresentaram como sendo uma experiência de interação que permitiu aos jovens pesquisados continuar interagindo, propondo e intervindo com ações nos seus respectivos coletivos de origem. O período destinado ao registo das narrativas compreendeu os meses de janeiro a junho de 2020, conforme cronograma de pesquisa aprovado anteriormente e foi seguido, mesmo com a deflagração da pandemia, considerado a orientação de uma etnopesquisa, onde o registro e análise do cotidiano e suas nuances na pesquisa é relevante e necessário.

Nesse contexto, Macedo (2010) descreve sobre o uso da imagem na pesquisa etnográfica, observando a necessidade de criar uma compreensão sobre a experiência vivida traduzida por elementos não-verbais. Assim sendo, a leitura de imagens, nesse caso, as narrativas criadas ou gerenciadas pelos jovens através dos dispositivos digitais, são parte das experiências de prolongamento do vivido no cotidiano. Serão observadas as narrativas dos jovens nos aplicativos ou redes sociais digitais, especialmente por meio do Instagram.

Ademais, em relação à análise das lives criadas pelos jovens, buscou-se inicialmente registrar a ocorrência dessas performances, destacando os diferentes assuntos debatidos e à diversidade de temáticas propostas nas mediações-lives, refletindo assim, a pluralidade de ações e objetivos dos/das jovens nos seus distintos coletivos de pertença e convívio. Buscou-se destacar como os atores/atrizes sociais juvenis, participantes desse estudo, vincularam informações, vídeos e imagens no Instagram, destacando assim, as formas de engajamento criadas por eles/elas, os modos de partilha e a implicação ativista em rede.

O estudo encontra-se em fase de produção dos dados e acompanhamento dos atores/atrizes da pesquisa por meio das ambiências virtuais. Ademais, constitui parte das investigações do Grupo de Estudos e Pesquisas em Informática na Educação (GEPIED/UFS/CNPq), especialmente nas linhas de pesquisa: Educação, Humanidade e Informática na Educação.

\section{A Espetacularização dos Corpos Juvenis nas Redes Sociais Digitais}

Tenho pensando sobre esse fenômeno das lives e da hipermobilidade como sendo um fenômeno da etnocenologia das aprendizagens juvenis em redes digitais. Há poucos dias comecei a pensar/escrever uma proposta de artigo que tem como objetivo explorar o conceito de mediações-lives e aprendizagens espetáculos. A ideia central consiste na ideia de que os jovens estão sendo, não só eles, atores e atrizes, protagonistas de cenários online e ao vivo com a finalidade de mediar, intervir, informar, divulgar e dialogar sobre os diversos temas que perfazem as temáticas dos coletivos ou temas de interesse pessoal. Usam as redes sociais digitais, especialmente os mecanismos online como forma de manter as relações e a projeção de suas ações com os demais pares. Para isso, praticam e ritualizam experiências com outros, usando os corpos e as linguagens em tempo real, mimetizando um tempo de aprendizagem que, desconstrói a ideia de hierarquia, fazendo emergir cenários etnocenológicos (extraordinários), verdadeiros espetáculos de interação e criação. (NOTA DO DIÁRIO DE BORDO DO PESQUISADOR, 24 DE MAIO DE 2020). Disponível em: https://www.evernote.com/shard/s621/sh/c93453c9-218b-4661-9ce3d99989bb8ace/9d1600ac85378bc477693cb97cb2a97f

A experiência de acompanhar os fenômenos dos jovens, por meio de uma etnopesquisa, conforme menciona Macedo $(2012$, 2015) revela um constante estado de alteração, reflexão e apreensão de sentidos que vão sendo criados, (des) construídos e negociados durante o caminhar com o objeto 
de estudo. Surgiu numa dessas passagens o registro no diário de intinerância (diário de bordo) ${ }^{3}$, como visto acima, destacando as experiências de espetacularização, por meio das lives, criadas pelos/pelas jovens.

O uso dessas engenharias informáticas fizeram surgir comportamentos inéditos, outras atitudes e maneiras de explorar a comunicação e os sentidos corporais formados por "[...] os elementos midiáticos e os coletivos humanos, arranjos sociais que se afloram em múltiplas redes de pertenças, corpos cibernéticos, cuja linguagem atravessa os dispositivos midiáticos e seus atos intersubjetivos" (SANTOS, 2019. p. 3).

Nestes cenários, os atores e atrizes jovens despontam, no Brasil e no mundo, como sendo os principais protagonistas de experiências utilizando os dispositivos de comunicação e interação digital. Os últimos dados apresentados pelo Comitê Gestor da Interne - CGI (2019) apontavam, antes da pandemia, que $94 \%$ das pessoas entre 16 e 24 anos, e $90 \%$ como faixa-etária entre 25 e 34 anos, dos indivíduos considerados jovens usam a internet por meio dos dispositivos moveis.

Nota-se que os jovens são aqueles que mais utilizam as redes para se comunicar, produzir conteúdos e estabelecer comunicação utilizando aplicativos videotransmissão (ao vivo). Schneider, Santos e Santos (2020) que o uso das tecnologias síncronas tornou o momento "propício para as experiências baseadas em conexões, resultado dos avanços tecnológicos em rede que, permite aos sujeitos sociais manterem-se conectados" (p. 42). O resultado desses imbricamentos das culturas juvenis com os dispositivos das culturas digitais fizeram surgir fenômenos variados, tanto na esfera privada, quanto pública, alterando decisivamente o cotidiano das relações humanas. (SIBÍLIA, 2018).

Sendo assim, ao observar o comportamento dos/das jovens nas redes sociais digitais notamos a emergência da espetacularização dos corpos, utilizados em ritualizações de processos comunicacionais com seus pares online. $\mathrm{O}$ acompanhamento dessas ações e suas dinâmicas nos convidam ir além de um olhar simplista que, corriqueiramente costuma-se "rotulá-las" como sendo resultado do uso efêmero ou banal das imagens pessoais dos atores/atrizes nas redes, sendo necessário demarcar aqui, que nestes rituais coabitam enunciados, narrativas, temas e assuntos que são acionados por meio de linguagens corporais nas redes, alimentadas por desejos protagonizados de intervenção performática.

Assim sendo, cumpre salientar que essas redes de afetos e performances são antes de tudo, agregações interconectadas, formadas por interesse em cultivar relações. É esclarecedor entendêlas como sendo redes inter-relacionais de comunicação-ação-intervenção. Como parte de um fenômeno maior, o qual chamamos de Etnocenologia Virtual da Aprendizagem Juvenil Contemporânea, estão situadas dentro dos apontamentos destacados por Carlson (2010) quando descreve que, as relações de comunicação contemplam a criação de performances e exibição de um comportamento para alguém.

Essa questão envolve, sobremaneira, a exponenciação das variadas experiências de engajamento possíveis de serem acompanhadas nas redes sociais digitais, por meio do acesso com os dispositivos comunicacionais ubíquos numa dimensão extraordinária de multiplicação de interações, verdadeiras "ambiências etnocenológicas". O uso dessas engenharias informáticas fizeram surgir comportamentos inéditos, outras atitudes e maneiras de explorar a comunicação e os sentidos corporais formados por [...] os elementos midiáticos e os coletivos humanos, arranjos sociais que se afloram em múltiplas redes de pertenças, corpos cibernéticos, cuja linguagem atravessa os dispositivos midiáticos e seus atos intersubjetivos, (SANTOS, 2019. p. 3).

Quando falamos em etnocenologia virtual dos comportamentos juvenis nas redes de interação virtualizadas, situamos o universo dos estudos desenvolvidos por Bião (2007) quando descreve a

\footnotetext{
${ }^{3}$ Registro de notas de campo com utilização do aplicativo Evernote.
} 
emergência dos estudos sobre os comportamentos humanos analisados a partir da noção de espetacularidade teatral e dramaturgia da vida cotidiana, mais que nunca, que provocam novas tessituras às relações humanas, especialmente no caso dos jovens, fazendo emergir narrativas, percepções e ações comunicativas de origem tribal, a exemplo dos fenômenos Net-ativistas estudados pelos autores Di Felice (2017), Mafessoli (2017; 2019), Santaella (2017; 2019), Roza e Melo (2017), entre outros.

A utilização das redes sociais como possibilidade de potencializar o discurso da diversidade tem como princípio a utilização desses espaços por serem territórios abertos, dinâmicos e democráticos. Em todo o caso, as redes sociais digitais estão sendo utilizadas como frequência para exploração de potencialidades comunicativas, produção e disseminação de conteúdos, divulgação de imagens, vídeos e informações usando o corpo, as falas e suas expressões. Esses mesmos jovens conhecidos pela cultura da exposição dos corpos, da intimidade e desejos, se agregam a outros em torno de ideias comuns e negociam sentidos nas redes, construindo e desconstruindo compreensões a partir de ações e atitudes.

Santaella (2017) ressalta o poder dessas redes para a transformação social e ainda que possam ser relativizadas por compreensões de alguns, suas consequências têm exercido um papel inegável, pois "[...] as redes continuam agindo em outros eventos pelo mundo, em alguns casos em sucesso, em outros como sendo alimento e de uma sensibilidade e esperança ativista" (p. 94).

Nesse quesito, as performances juvenis, originadas na cibercultura tornam-se elementos de inconteste importância, por suas características complexas dentre elas, a multiplicidade de fenômenos que as circunda. Não obstante, existe uma consensualidade em delimitar o universo da performance como sendo uma motivação (pessoal ou coletiva) de alcançar o outro, usando ações comunicativas corpóreas. Entende-se aqui, por ações comunicativas corpóreas, a dimensão indivisível do corpo em sua totalidade. Nesse escopo, o corpo ganha lugar de destaque, como sendo o meio de criá-las. Grosso modo, ele é o "palco" usado pelos atores sociais para cultivar imagens performáticas, conforme salienta Santos e Schneider (2019):

Nesse limiar, em decorrência do uso exponencial e multimodal das TDIC por jovens, o resultado da hibridização dos corpos e linguagens em larga escala, por intermédio de dispositivos tecnológicos, nos leva a refletir sobre a vivência de um comportamento fora da curva até então não observado na história humana, podendo ser definido como um comportamento espetacular, independente do juízo que se faça dele (p. 8).

Em tempos de hibridismos, esses corpos humanos multifacetados por linguagens digitais na cibercultura, criam nas variadas ambiências com o digital, infinitos arranjos e repertórios comunicativos. Nas redes, os dispositivos de convergência das linguagens mesclam o uso de vídeos, sons, imagens que, ao serem renderizadas ${ }^{4}$ formam conteúdos expressivos, inéditos e autorais buscando mediar a experiência cotidiana, criando vínculos anunciativos e transgressores.

\section{Mediações-Lives nas Redes: performando experiências de Criação, interação e aprendizagens coletivas}

Segundo Goffman (2011) uma performance pode ser entendida como qualquer atividade onde um determinado participante atua como influenciador dos demais. Isso implica dizer que a performance se relaciona com uma ação prática que passa a ser observada por outras pessoas. Pode-se destacar ainda que, para o autor a performance funciona como uma estrutura de comportamento, onde uma pessoa executa determinado papel, fazendo surgir dessa ação uma 
relação social que pode definir, por exemplo, um papel de homem ou mulher, mas não se limitando ao ordenamento desse papel, uma vez que a performance abre espaços para que o performer possa interpretar vários papéis em diferentes contextos de interação social. É sobre essa experiência que nos interessa a definição do conceito de performances no âmbito das redes sociais digitais.

O sentimento de que "a performance está em todos os lugares" aumenta por causa de um ambiente mediado, onde as pessoas se comunicam por fax, por telefone, e pela internet, onde uma quantidade ilimitada de informação chega pelo ar (SCHECHNER, 2006, p. 23).

Desse modo, entender as experiências das performances dos atores sociais nas ambiências virtuais (nas redes) é caminho necessário para melhor entender tal fenômeno. Desse modo, as redes sociais resultam do aperfeiçoamento técnico dos sistemas de comunicação que não se limitam mais a vinculação apenas de textos escritos. Nas palavras de SANTOS (2015, p. 35) "São valiosos espaços de aparição da socialidade, onde se encontram a presença de transgressores afetivos e os aglomerados urbanos, midiáticos e planetários dispostos em redes de pertencimento nos diversos cantos do mundo".

Pode-se destacar que as redes sociais tiveram em sua formação uma relação direta com a organização de comunidades por interesses afins, que integram os mecanismos de seus surgimentos até hoje, com destaque para os princípios de autoria, cooperação, co-criação, sensibilidade e atração, possíveis com o refinamento dos dispositivos, cada vez mais intuitivos, moveis e conectados.

No contexto das performances criadas pelos/pelas jovens nas redes sociais digitais durante a pandemia, destacam-se diversas experiências e estilizações. Notou-se o uso de recursos disponíveis no Instagram $^{5}$, como, por exemplo a criação e edição de vídeos na extensão IGTV a criação de chamadas e séries específicas para divulgar trabalhos relacionados aos coletivos ativistas que fazem parte, criação de conteúdos em rádios virtuais para debater assuntos relacionados a arte, cultura e os desafios de pensar o futuro depois da pandemia.

Nesse caminho, as lives fizeram/fazem parte desses cenários de estilizações das performances juvenis no decorrer da pandemia. Notadamente, esse foi um recurso muito utilizado por famosos e anônimos para informar, dialogar, refletir, entreter, etc. Por sua facilidade de execução e possibilidade de gerar engajamento, as transmissões nas redes sociais digitais ganharam lugar de destaque entre os jovens, como sendo um caminho fecundo co-criação de vídeos-imagens de si em conversas formativas que buscam quebrar uma formalidade notada em outras propostas de interação online. Nestes fenômenos, são observadas um conjunto de características qualitativas relevantes que, endossam às provocações investigativas, em curso. Segundo Santos (2020):

Lives são transmissões síncronas de conteúdo em forma vídeo online. Esses vídeos se materializam em diversas metodologias. Transmissões de conteúdos individuais e ou coletivos. Muitas vezes, com interação direta em diferentes plataformas e redes sociais ou em convergências com outras interfaces de textos, a exemplo dos chats (salas de batepapo). (Online).

Além disso, criam conteúdos para debater temas comuns às dinâmicas dos agrupamentos que fazem parte, tais como diversidade, religião, violência contra mulher, preconceito, crise política

\footnotetext{
${ }^{5}$ Rede social pertencente ao Fecebook, utilizada por $27 \%$ da população brasileira conectada, segundo dados do informe (2018) da Comissão Econômica para a América Latina e o Caribe- CEPAL. Segundo dados do Instagram (2020), o Brasil tem 82 milhões de contas ativas, com maior público usuário, na faixa-etária entre 18 e 34 anos.

${ }^{6}$ Aplicativo de criação, edição e disponibilização de vídeos pertencente ao Facebook, lançado em 2018. Pode ser usado como parte dos serviços embarcados no aplicativo Instagram.
} 
no Brasil foram alguns dos destaques que compuseram as "imagens-performances" desses jovens, inclusive com uso do próprio corpo. Não obstante, os/as jovens participantes da pesquisa ritualizaram memes, charges boletins informativos (denunciativos e formativos) sobre a pandemia do novo coronavírus, visando à disseminação de notícias verdadeiras nas suas redes.

É nesse sentido chamamos atenção para o elemento da mediação propositiva entre os jovens que criam esses cenários espetaculares ao vivo. Utilizamos o termo mediações-lives por entender que estas resultam de ações comunicativas inter-pares, compreendendo uma cartografia aberta ao diálogo, compartilhamento, escuta e conhecimento do outro, negociação de sentidos e esclarecimento de pontos divergentes/convergentes, dentro de uma proposta que, embora criada como anúncio, tem em sua dimensão o elemento dinâmico do inédito.

Quando se destaca a ideia de mediação dos jovens em rede, se quer chamar atenção para a figura do usuário participante e interlocutor de uma determinada atividade. $\mathrm{O}$ ato de mediar, como salienta Thadei (2018) requer envolvimento das partes, o exercício de um "estar entre" evolvendo demandas extremas, distintas vozes e uma colaboração que ajuda a formar um todo significativo. O elemento digital e a radicalidade possível com a mobilidade das experiências nos dispositivos de acesso ao ciberespaço, forjaram mediações desterritorializadas, permitiram não só o encurtamento das distâncias, a flexibilizando a explorarão de novas relações aproximativas, o convívio e cultivo de narrativas online, dentro de um quadro não estável, ao contrário fluido, controverso e tensionado pelas diferentes formas de comunicação por distintos agrupamentos que formam um "caleidoscópio das imagens" criadas no cotidiano dos/das jovens ao mediar as suas narrativas e experiências.

Não obstante, a necessidade de adaptação da população mundial ao isolamento/distanciamento social, a limitação (presencial) das possibilidades de interação nos permitiu acompanhar diferentes maneiras de adaptação da vida contingenciada pela crise de saúde. Essa adaptação, com contornos problemáticos e diferentes interpretações fez dos espaços de interação virtualizados, um caminho criativo para prensar o porvir. Ao nosso ver, as mediaçõeslives são fecundas ações estilizadas pelos/pelas jovens no conjunto de seus repertórios comunicacionais e podem ser entendidos/potencializados no cultivo das aprendizagens, sobremaneira, por serem ambiências de interações que lidam com assuntos, temas, debates que se mesclam e intercruzam com conhecimentos científicos.

Suas performances variam em função do momento, assuntos em destaque com projeções nacionais, locais e mundiais. Modificam também de acordo com as diferentes formas de expressão, prezando por uma comunicação propositiva, esteticamente pensada para engajar temas que já faz parte da natureza dos coletivos ou questões que abarcam assuntos que implicam a coletividade societal. Não é intenção desse trabalho esgotar em detalhes as experiências que figuram o fenômeno da Etnocenologia Virtual da Aprendizagem Juvenil Contemporânea, uma vez que se trata de estudo em andamento. Aqui, será priorizado uma das experiências que abrange esse panorama, por sua natureza episódica e extraordinária das mediações-lives, ritualizadas "ao vivo". As imagens abaixo, demonstram algumas experiências protagonizadas pelos/pelas jovens durante a pandemia, com autorização expressa em Termo de Consentimento Livre e Esclarecido - TCLE, em posse dos pesquisadores que conduzem o estudo. 


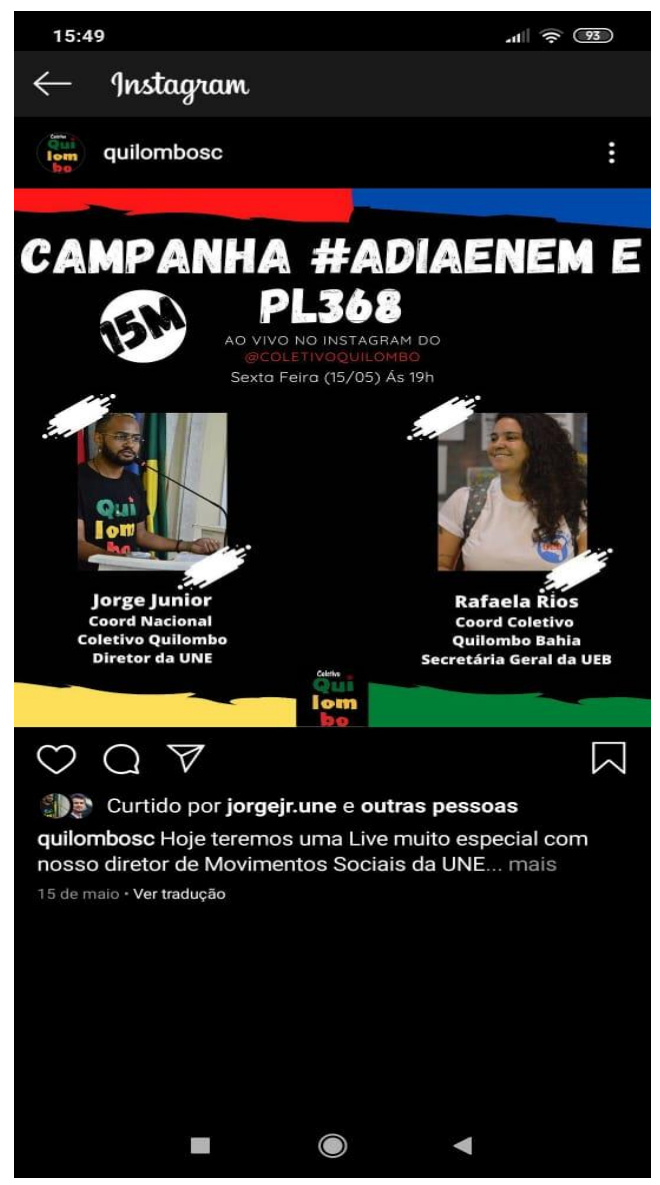

Figura 1: Post da live no stories de @ jorgejr.une (Maio de 2020).

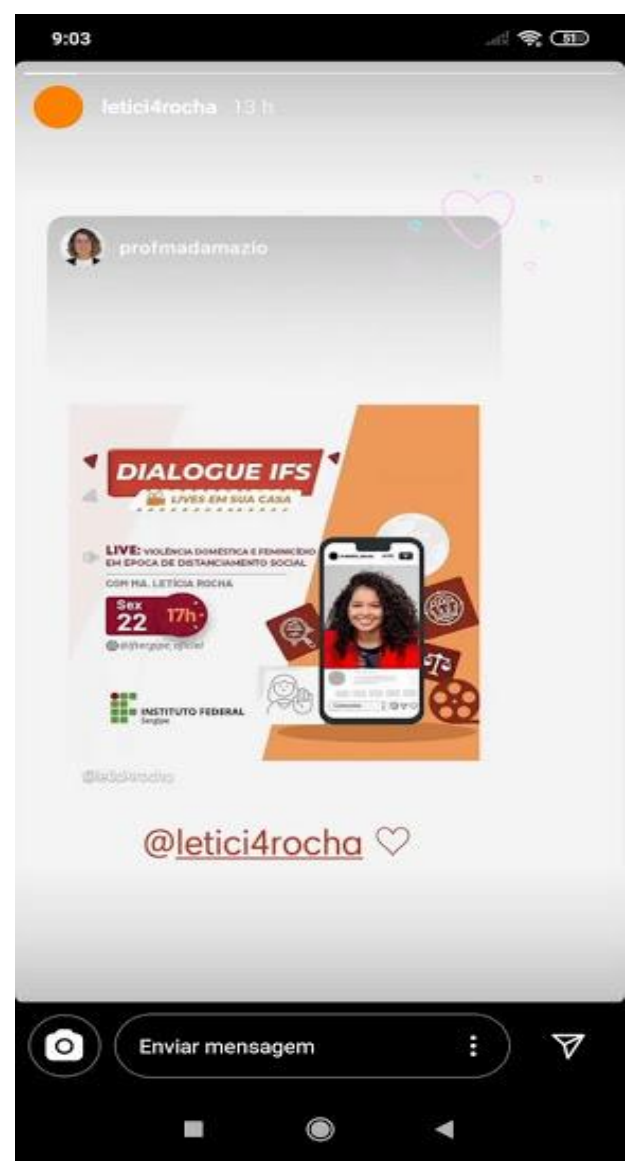

Figura 3: Post da live no stories de @ leti4rocha (Maio de 2020).

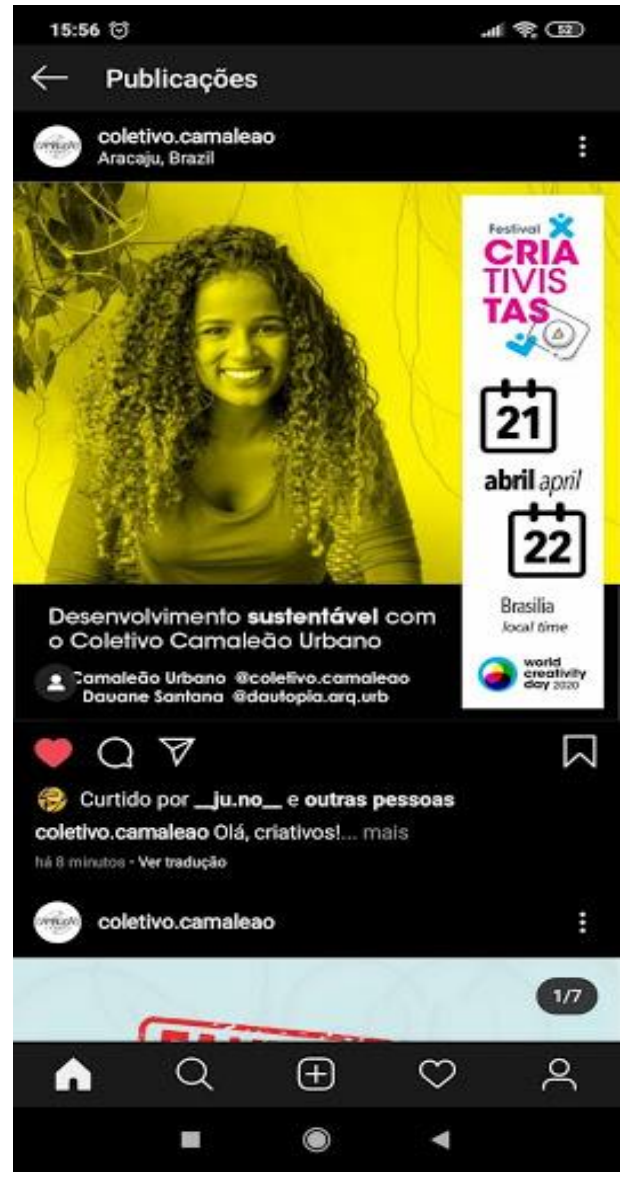

Figura 2: Post da live no stories de @ dautopia.arq.urb (Abril de 2020).

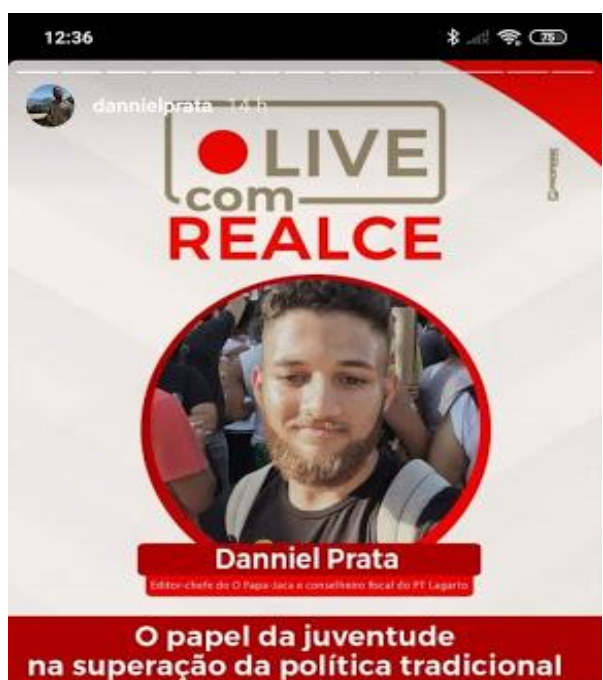

na superação da política tradicional

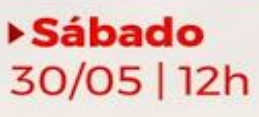

(0)@revistarealce IRealce

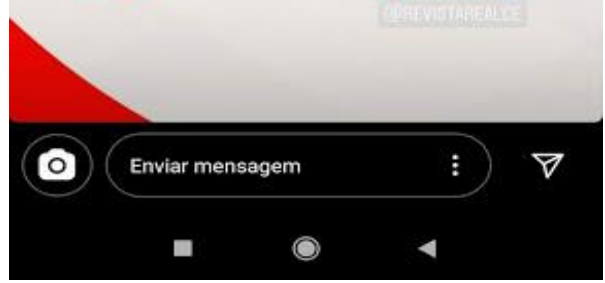

Figura 4: Post da live no stories de @ dannielprata (Maio de 2020). 


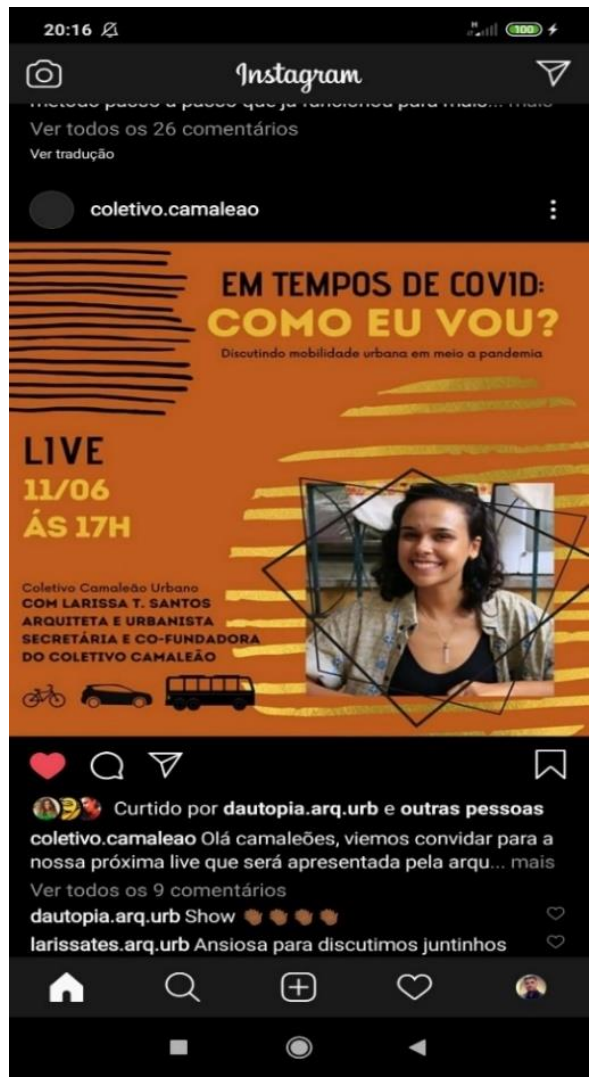

Figura 5: Post da Live no Stories @ larissates.arq.urb (Junho de 2020).

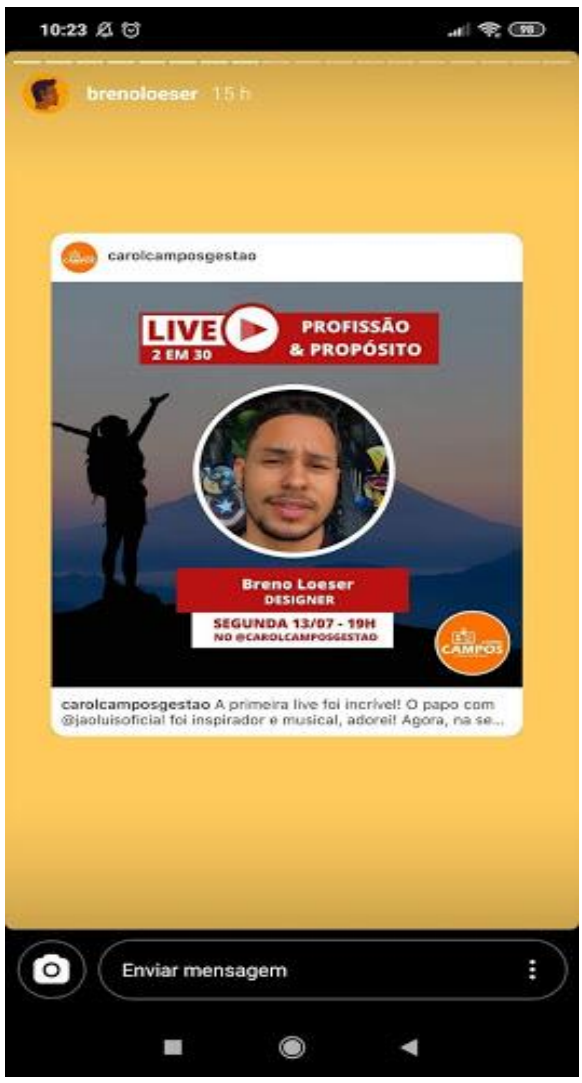

Figura 6: Post da Live no Stories de @ brenoloeser (Julho de 2020).

Outro ponto que torna essas experiências extraordinárias, consiste no seu caráter público, qualquer pessoa, em síntese, pode ter acesso ao vídeo, desde que acionada na rede de um seguidor. O efeito disseminador (viral) da rede, a partir da ideia de convites, cria um mecanismo reticular potencial de multiplicação dos pontos e a exponenciação da comunicação originária. Segundo Di Felice (2017) esse efeito de comunicação reticular assume a complexidade das ações desenvolvidas "[...] nas redes digitais, conectados a dispositivos, circuitos elétricos, banco de dados e às demais pessoas, por sua vez, conectadas a dispositivos circuitos elétricos, banco de dados e outras pessoas", (p. 14). Cumpre destacar que, no universo dos/das jovens que fazem parte desse estudo, os mecanismos de mediações-lives foram utilizados em 16 eventos, conforme indicado no detalhamento de informações abaixo:

Tabela 1: Lives protagonizadas pelos/pelas jovens da pesquisa, durante a pandemia, (Até julho de 2020).

\begin{tabular}{|c|c|c|c|}
\hline $\begin{array}{c}\text { Ator/atriz jovem } \\
\text { protagonista/ } \\
\text { Mediador } \\
\end{array}$ & Tema da Live & Dia e horário do evento & $\begin{array}{c}\text { Total de } \\
\text { engajamentos gerados } \\
\text { com a ação: }\end{array}$ \\
\hline $\begin{array}{l}\text { Rafael Catchup } \\
@ \text { rafaelcatchup }\end{array}$ & $\begin{array}{l}\text { O movimento digital } \\
\text { dos artistas } \\
\text { Duração: Não consta. }\end{array}$ & $\begin{array}{l}\begin{array}{c}20 \text { de Abril de } 2020 \text { às } 19 \mathrm{~h} \\
\text { no Instagram. Link do } \\
\text { cartaz: }\end{array} \\
\frac{\text { https://www.instagram.com/ }}{\text { p/B FyeOBBWjT/?igshid=j }} \\
\underline{\text { xq4me1r9k21 }}\end{array}$ & $\begin{array}{c}259 \text { curtidas, } 21 \\
\text { comentários. }\end{array}$ \\
\hline $\begin{array}{c}\text { Dauane Santana } \\
\text { @ dautopia.arq.ur } \\
\text { b }\end{array}$ & $\begin{array}{c}\text { Desenvolvimento } \\
\text { Sustentável com o } \\
\text { Coletivo Camaleão } \\
\text { Urbano. } \\
\text { Duração: Não consta. }\end{array}$ & $\begin{array}{c}21 \text { de abril de } 2020 \text { às } 19 \mathrm{~h} \\
\text { no Instagram. } \\
\text { Link do cartaz: } \\
\frac{\text { https://www.instagram.com/ }}{\text { p/B_OLYOrBcIn/?igshid=1 }} \\
\underline{\text { 7q7j1a5a4wzo }}\end{array}$ & $\begin{array}{l}115 \text { curtidas, } 3 \\
\text { comentários. }\end{array}$ \\
\hline Danniel Prata & $\begin{array}{c}\text { Roda de Conversa } \\
\text { Duração: Não consta. }\end{array}$ & $\begin{array}{l}\text { 21de Abril de } 2020 \text { às } 19 \mathrm{~h} \\
\text { no Link do cartaz: }\end{array}$ & 105 curtidas. \\
\hline
\end{tabular}




\begin{tabular}{|c|c|c|c|}
\hline @dannielprata & & $\begin{array}{l}\frac{\text { https://www.instagram.com/ }}{\text { p/B_PXP8yFpce/?utm_sourc }} \\
\text { e=ig_web copy link }\end{array}$ & \\
\hline $\begin{array}{l}\text { Jorge Junior } \\
\text { @jorgejr.une }\end{array}$ & $\begin{array}{l}\text { O Ensino Superior em } \\
\text { Tempo de Coronavírus } \\
\text { Duração: } 59 \mathrm{~m} 23 \mathrm{~s}+ \\
\text { 31m34s. } \\
\text { Duração: Não consta. }\end{array}$ & $\begin{array}{c}\begin{array}{c}21 \text { de Abril de } 2020 \text { às } \\
\text { 18:30h no Instagram. Link } \\
\text { do vídeo: }\end{array} \\
\frac{\text { https://www.instagram.com/t }}{\text { v/B_a5lLyhqWd/?igshid=10 }} \\
\frac{\text { n8rzw3rbgju }}{\text { nry }}\end{array}$ & 6 visualizações. \\
\hline $\begin{array}{l}\text { Jorge Junior } \\
\text { @jorgejr.une }\end{array}$ & $\begin{array}{c}\text { Importância da } \\
\text { Educação, Ciência e } \\
\text { Tecnologia para } \\
\text { combater a Covid-19. } \\
\text { Duração: Não consta. }\end{array}$ & $\begin{array}{c}\begin{array}{c}22 \text { de abril de } 2020 \text { às } 14 \mathrm{~h} \\
\text { no Instagram. Link do } \\
\text { cartaz: }\end{array} \\
\frac{\text { https://www.instagram.com/ }}{\mathrm{p} / \mathrm{B} \mathrm{Q}-} \\
\frac{\text { RsiH7YV/?igshid }=\mathrm{xdr} 11 \mathrm{gfz}}{\mathrm{adnp}}\end{array}$ & $\begin{array}{l}51 \text { curtidas, } 2 \\
\text { comentários. }\end{array}$ \\
\hline $\begin{array}{l}\text { Jorge Junior } \\
@ \text { jorgejr.une }\end{array}$ & $\begin{array}{l}\text { O papel do movimento } \\
\text { Estudantil na Pandemia } \\
\text { Duração: Não consta. }\end{array}$ & $\begin{array}{l}06 \text { de Maio de } 2020 \text { às } 14 \mathrm{~h} \\
\text { no Instagram. Link do } \\
\text { cartaz: } \\
\frac{\text { https://www.instagram.com/ }}{\text { p/B 2KdUTh 9/?igshid=i9 }} \\
\text { tw3rqr9oug }\end{array}$ & 54 curtidas. \\
\hline $\begin{array}{l}\text { Jorge Junior } \\
@ \text { jorgejr.une }\end{array}$ & $\begin{array}{c}\text { Campanha \#Adiaenem } \\
\text { e PL368 } \\
\text { Duração: Não consta. }\end{array}$ & $\begin{array}{l}\begin{array}{c}15 \text { de Maio de } 2020 \text { às } 19 \mathrm{~h} \\
\text { no Instagram. Link do } \\
\text { cartaz: }\end{array} \\
\frac{\text { https://www.instagram.com/ }}{\text { p/CAOLIgzHSjy/?igshid=1ji }} \\
\underline{13 \text { fim } 70 \mathrm{fv}}\end{array}$ & 32 curtidas. \\
\hline $\begin{array}{l}\text { Danniel Prata } \\
@ \text { dannielprata }\end{array}$ & $\begin{array}{l}\text { ENEM e Desigualdade } \\
\text { Social: construindo } \\
\text { pautas para além do } \\
\text { conhecimento } \\
\text { Duração: } 59 \mathrm{~m} 26 \mathrm{~s}+ \\
\text { 30m52s }\end{array}$ & $\begin{array}{l}22 \text { de Maio de } 2020 \text { às } 14 \mathrm{~h} \\
\text { no Instagram. Link do vídeo: } \\
\frac{\text { https://www.instagram.com/t }}{\text { v/CAgBgwFhAqO/?igshid }=} \\
\underline{\text { 1srgoie5ypekn }}\end{array}$ & $\begin{array}{c}656 \text { visualizações, } 4 \\
\text { comentários. }\end{array}$ \\
\hline $\begin{array}{l}\text { Letícia Rocha } \\
\text { @leti4rocha }\end{array}$ & $\begin{array}{l}\text { Violência Doméstica e } \\
\text { Feminicídio em época } \\
\text { de distanciamento } \\
\text { social } \\
\text { Duração: } 55 \mathrm{~m} 48 \mathrm{~s} \text {. }\end{array}$ & $\begin{array}{c}22 \text { de Maio de } 2020 \text { às } 17 \mathrm{~h} \\
\text { no Instagram. Link do } \\
\text { vídeo: } \\
\frac{\text { https://www.instagram.com/t }}{\text { v/CAgSS51B2ef/?igshid=pi }} \\
\frac{\text { w1xg70ws30 }}{}\end{array}$ & $\begin{array}{c}742 \text { visualizações, } 6 \\
\text { comentários. }\end{array}$ \\
\hline $\begin{array}{l}\text { Danniel Prata } \\
\text { @dannielprata }\end{array}$ & $\begin{array}{l}\text { O papel da Juventude } \\
\text { na Superação da } \\
\text { política tradicional. } \\
\text { Duração: } 55 \mathrm{~m} 34 \mathrm{~s}\end{array}$ & 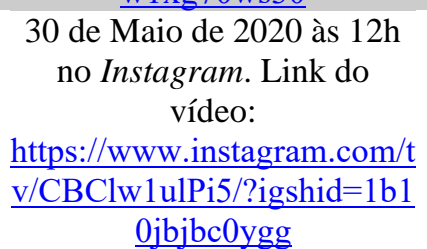 & 1.648 visualizações. \\
\hline $\begin{array}{l}\text { Rafael Catchup } \\
\text { @rafaelcatchup }\end{array}$ & $\begin{array}{l}\text { Ansiedade, aprenda a } \\
\text { lidar com ela. } \\
\text { Duração: } 57 \mathrm{~m} 49 \mathrm{~s}\end{array}$ & $\begin{array}{c}\text { 02 de Junho de } 2020 \text { às } \\
\text { 19:30h no Instagram. Link } \\
\text { do vídeo: } \\
\text { https://www.instagram.com/t } \\
\frac{\text { v/CA84uCQB4L3/?igshid=1 }}{\text { oevc5ss4pvq3 }}\end{array}$ & $\begin{array}{c}654 \text { visualizações, } 2 \\
\text { comentários. }\end{array}$ \\
\hline $\begin{array}{l}\text { Danniel Prata } \\
\text { @ dannielprata }\end{array}$ & $\begin{array}{l}\text { Assédio na Escola: por } \\
\text { quê quebrar o silêncio é } \\
\text { necessário? } \\
\text { Duração: } 59 \mathrm{~m} 37 \mathrm{~s}\end{array}$ & 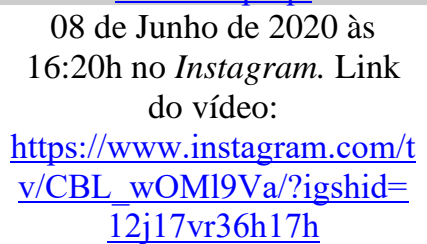 & $\begin{array}{c}975 \text { visualizações, } 7 \\
\text { comentários. }\end{array}$ \\
\hline Larissa Santos & $\begin{array}{l}\text { Em tempos de Covid: } \\
\text { como eu vou? } \\
\text { Discutindo mobilidade }\end{array}$ & $\begin{array}{c}11 \text { de junho } 2020 \text { às } 17 \text { ho no } \\
\text { Instagram } \\
\text { Link do cartaz: }\end{array}$ & \\
\hline
\end{tabular}




\begin{tabular}{|c|c|c|c|}
\hline $\begin{array}{l}\text { @ larissates.arq.ur } \\
\mathrm{b}\end{array}$ & $\begin{array}{c}\text { urbana em meio a } \\
\text { pandemia. } \\
\text { Duração: Não consta. }\end{array}$ & $\frac{\frac{\text { https://www.instagram.com/ }}{\text { p/CBBxomwBrY5/?igshid= }}}{\text { 4sdqmzbcvkmn }}$ & $\begin{array}{l}103 \text { curtidas, } 14 \\
\text { comentários. }\end{array}$ \\
\hline $\begin{array}{l}\text { Danniel Prata } \\
\text { @ dannielprata }\end{array}$ & $\begin{array}{c}\text { O avanço do } \\
\text { Coronavírus em } \\
\text { Lagarto } \\
\text { Duração: } 48 \mathrm{~m} 43 \mathrm{~s}\end{array}$ & $\begin{array}{c}\begin{array}{c}15 \text { de Junho de } 2020 \text { às } \\
\text { 17:30h no Instagram. Link } \\
\text { do vídeo: }\end{array} \\
\frac{\text { https://www.instagram.com/t }}{\text { v/CBeHx3ZFO9k/?igshid=1 }} \\
\text { fr9huqvhnq4w }\end{array}$ & $\begin{array}{c}1.728 \text { visualizações, } 18 \\
\text { comentários. }\end{array}$ \\
\hline $\begin{array}{l}\text { Danniel Prata } \\
\text { @dannielprata }\end{array}$ & $\begin{array}{c}\text { O desafio de ser } \\
\text { LGBTQ+ em espaços } \\
\text { hegemonicamente } \\
\text { heterossexuais } \\
\text { Duração: } 59 \mathrm{~m} 57 \mathrm{~s} \text {. }\end{array}$ & $\begin{array}{c}\begin{array}{c}23 \text { de Junho de } 2020 \text { às } \\
\text { 16:20h no Instagram. Link } \\
\text { do vídeo: }\end{array} \\
\frac{\text { https://www.instagram.com/t }}{\text { v/CByoThjFnPn/?igshid=1g }} \\
\text { kxzofb0b50 }\end{array}$ & $\begin{array}{l}629 \text { visualizações, } 3 \\
\text { comentários. }\end{array}$ \\
\hline $\begin{array}{l}\text { Breno Loeser } \\
@ \text { brenoloeser }\end{array}$ & $\begin{array}{l}\text { Profissão e Próposito. } \\
\text { Duração: } 41 \mathrm{~m} 28 \mathrm{~s}\end{array}$ & $\begin{array}{l}\begin{array}{c}13 \text { de Julho de } 2020 \text { às } 19 \mathrm{~h} \\
\text { no Instagram. Link do } \\
\text { vídeo: }\end{array} \\
\frac{\text { https://www.instagram.com/t }}{\text { v/CCmXWY8IJjO/?igshid= }} \\
\frac{1 \mathrm{rmmg} 8 \mathrm{hk} 2 \times 64 \mathrm{~g}}{}\end{array}$ & 237 visualizações. \\
\hline
\end{tabular}

Por terem uma duração por evento de uma hora, determinação de fluxo permitida pelo Instagram, alguns jovens optam por fazer outra reconexão da mesma live. Por isso, nota-se na tabela o somatório do tempo de algumas experiências. Nas experiências ao vivo, os jovens estiveram à frente do processo ou fizeram parte de uma interlocução com outros atores/atrizes mediadores. Todavia, em todas elas, é possível notar o protagonismo dos/das mesmos/mesmas. Conforme observado acima, pelo menos seis dos/das dez jovens do estudo cultivaram performances por meio de mediações-lives desde o início da pandemia. Os/s jovens que não ritualizam essas performances se envolveram com outras dinâmicas nas redes, a exemplo de campanhas e desafios, festivais, criação de conteúdos em rádio online, edição de revistas digitais, sem contar com as diversas imagens-enunciados e muito mais. Esses fenômenos ou estilizações serão mais bem detalhados com análises das narrativas criadas nas análises da investigação em andamento, sendo possível nesse momento destacar os contornos, inferências e diálogos com os caminhos, conceitos e achados do estudo.

Como parte dos achados nas experiências dos/das jovens nas ambiências virtuais, esses espetáculos (as mediações-lives e aprendizagens etnocenológicas) são organizados a partir de um tema, encontro ou proposição (podendo ser entre pares), criando antecipadamente um anúncio, um chamariz para o espetáculo performático que tem dia, hora e aplicativo definido, nesse caso o Instagram. Um dos elementos que chama atenção desse fenômeno é o processo de descoberta, escuta e intersecção com narrativas de atores e atrizes já conhecidos e previamente identificadas pelo processo de busca/escolha nas redes sociais digitais. Tal como a vida, no cotidiano, as experiências espetaculares nas lives atraem os olhares, as intenções e podem desencadear interações capazes de criar mediações agregadoras de conhecimentos.

Sendo assim, as mediações-lives compreende a exploração dos corpos envolvidos, tanto aqueles que estão à frente da exposição, bem como os outros que assistem, podem comentar ou mesmo refletir sobre as narrativas divulgadas no espaço-tempo (ao vivo). Com base na observação dos/das jovens participantes da pesquisa, criamos o seguinte esquema que poderá ajudar no entendimento das características performáticas dos/das jovens nas redes, dentre elas as mediaçõeslives:

Tabela 2: Performances Juvenis Nas Redes Sociais Digitais, criação dos autores (julho de 2020). 


\begin{tabular}{|c|c|}
\hline $\begin{array}{l}\text { Elementos } \\
\text { envolvidos }\end{array}$ & Atores sociais (performers juvenis em rede na internet) \\
\hline Construção & Rituais nas redes com uso dos dispositivos digitais e convergentes. \\
\hline Sustentação & $\begin{array}{l}\text { Associação por interesse por meio de sentimentos pulsionais, imagéticos } \\
\text { e narrativas comunicacionais. Uso de vários símbolos, códigos nos } \\
\text { espaços de atualização do virtual. (Lógica da convergência e ubiquidade) }\end{array}$ \\
\hline Técnicas & Livre associação indeterminação. Uso livre de objetos - espaço - tempo. \\
\hline Características & $\begin{array}{l}\text { Narrativas baseadas em linguagens líquidas e imagéticas (artísticas, } \\
\text { plásticas, políticas, poéticas de cunho enunciativo e denunciativo). }\end{array}$ \\
\hline Formas de atração & $\begin{array}{l}\text { Os atores sociais juvenis interagem em rede, criando relações } \\
\text { comunicacionais coletivas baseadas na (atração, repulsão, aproximação, } \\
\text { afastamento, recusa). O trabalho assume uma formação coletiva e } \\
\text { colaborativa. }\end{array}$ \\
\hline Local de apresentação & $\begin{array}{l}\text { No cotidiano das ambiências de interação e convívio (virtuais e } \\
\text { presenciais), difundidas e exploradas principalmente nas redes sociais } \\
\text { digitais. }\end{array}$ \\
\hline Temporalidade & $\begin{array}{l}\text { Episódicos, fluidos e constantes, a depender do objetivo e interesse } \\
\text { comunicativo. (Se multiplicam no cotidiano das virtualidades pelo } \\
\text { ciberespaço). }\end{array}$ \\
\hline
\end{tabular}

Essas experiências, conforme destaca Martín-Barbero (2008, 2018), são parte de "saberes mosaicos" e revelam os cenários potenciais que podem ser criados com variadas intenções e rompem com as lógicas das mídias clássicas, construindo espaços fragmentados de reunião, dispersão, convívio e engajamento juvenil. Segundo Johnson (2003) o autogerenciamento das condutas humanas nesses espaços de interação multidimensionais onde sobressaltam aos olhos pequenos movimentos periféricos que traduzem vida pulsante, baseados em comportamentos descentralizados, coletivos de natureza inteligente numa dinâmica buttom-up. Demarcam a ideia de criação personalizada, definida por Tapscoot (2010), Jenkins (2008) e Prensky (2006) como sendo ações prosumers inter-relacionadas.

Desse modo, é condição necessária conhecer os processos que compõem as aprendizagens com uso dos dispositivos digitais, em especial, por sua natureza disruptiva e propositiva, tão necessária à escola que, precisa com celeridade criar meios de estilizar a educação, cultivando outras lógicas de mediação dos saberes e conhecimentos numa dimensão complexa, coletiva, colaborativa, partilhada, online e (ao vivo), o que envolve propor alternativas estilizadas durante e para além da pandemia. Essas ideias são corroboradas por Santos, Santos e Nunes (2019) como sendo "[...] experiências coletivas, ecológicas e organizadas por meio de encontros (virtuais e presenciais) que suscitam outras práticas socioeducativas".

É oportuno dizer que essas ações comunicativas são parte de uma educação sociocultural situada no contexto de hipermobilidade, tensionada pelos efeitos da situação emergencial de saúde. Como tal, favorecem a criação de outras lógicas, cenários, e, sobretudo, maneiras de entender a educação, flexibilizando as maneiras de relacionar-se com os pares envolvidos, a partir de trilhas, dispositivos e aplicativos diversificados que consigam impulsionar não o acompanhamento e certificação dos conteúdos, mas sim, primando pela autonomia autoral dos/das atores/atrizes envolvidos, jovens ou não, para pensar juntos e coletivamente os processos das aprendizagens, suas descobertas e caminhos.

Sendo assim, tomando como exemplo as redes de atração coletiva dos jovens pesquisados, chamamos atenção para um traço, ao nosso ver, imprescindível, quando projetamos cenários de interação educacional na pandemia. Os/as jovens formam redes de colaboração, cumplicidade e apoio nas ações presenciais e nas redes também. Esses eventos episódicos, ritualizam por meio do compartilhamento proativo e exponenciação das experiências nas redes de atração e convívio. 


\section{Considerações Provisórias}

No contexto destes cenários cotidianos de imersão e criação, a educação se faz como resultado das experiências e aprendizagens em fluxos, imagens, sons, vídeos, relações e interações engajadas. As informações e os espaços de virtualidade são os cenários onde as expressões e significados são partilhados por diferentes coletivos nas redes, aqui especificamente as redes de autoria dos/das jovens, visto como sendo protagonistas de variadas performances de aprendizagens que remodelam e criam ambiências cenológicas de partilha.

Nesses rituais de engajamento por sensibilidade as tecnologias informáticas, os dispositivos digitais, seus inúmeros formatos e écrans conectados em redes, pessoas desterritorializadas no tempo-espaço, mas unidas por princípios, ideais comuns e sentimentos comuns mobilizam-se na internet, baseados numa temporalidade que pode variar, dependendo da ação, intuito ou proposta.

Dessa maneira, é prudente atenuar o olhar pelo qual, costumados olhar as práticas juvenis nas redes sociais digitais, em muitos casos associadas com posturas banais ou sem validade, segundo um olhar normativo. De outro modo, sugere uma postura compreensiva capaz de aproximar-se das linguagens e caminhos criados por estes, no sentido de viver suas experiências, dos diversos cenários de suas vidas cotidianas, incluído aí, os coletivos virtuais onde convivem e pertencem.

Todavia, do ponto de vista da abrangência, função e prolongamento das experiências online, pode-se dizer que as lives resultam de ação potencial, episódica que tem como possibilidade o prolongamento de experiências como alternativa de criar estratégias, metodologias de comunicação, como foi possível observar com os jovens. Outro traço interessante desse fenômeno consiste em notar como os/as jovens e os respectivos coletivos que fazem parte, propuseram esses eventos-performances como forma de manter vínculos os afetivos, emocionais, profissionais, acadêmicos, etc, durante a pandemia da COVID-19. Ademais, é possível chamar atenção que, no caso desses/dessas jovens, as mediações-lives já faziam parte de seus repertórios de comunicação nas redes, sendo intensificadas nos últimos meses.

Caber mencionar que este trabalho é resultado de um estudo em andamento e suas análises torna-se-ão mais profundas à medida que cruzadas com dados produzidos utilizando outros dispositivos de pesquisa, a exemplo das entrevistas realizadas com os/as jovens que, ajudarão a entender os limites e o entendimento desse fenômeno social. Ademais, cabe destacar que os desenhos e cartografias dos/das jovens nessas incursões de vida-formação deixam transparecer que a ideia de convívio, criação de laços e performances das aprendizagens se relacionam com os usos das linguagens codificadas com os dispositivos digitais da cibercultura, e como tais, deslocam o entendimento que se tem da educação, criando em paralelo, possibilidades de construção, (des) construção), autoria e criação colaborativa.

Logo, falar em educação nesse contexto requer entender os espaços das vivências sociais, ampliando sua dimensão para os diferentes lugares de interconexão, convívio, a exemplo de ambiências virtuais que dão outros sentidos às experiências de aprendizagens. Ouvir esses jovens e entender o que pensam e fazem é condição necessária para entender suas ações comunicativas e como estas expressam significados que são partilhados em redes de colaboração, engajamento e sensibilidade, permitindo assim, um redesenho e criação de alternativas capazes de potencializar as experiências de aprendizagens que cercam os espaços escolares. Ressignificar a sala de aula, tomando como exemplo as formas de organização dos/das jovens utilizados os dispositivos digitais para criar, intervir e alterar à realidade é certamente um desafio promissor aos educadores e instituições de ensino.

No contexto desse fenômeno, as mediações como os dispositivos e as narrativas criadas pelos jovens, são um chamariz para investigar as performances etnocenológicas de aprendizagens e 
como estas criam cenários e caminhos para a educação na atualidade. Portanto, as mediaçõeslives são proposições (ações-intervenções) da vida cotidiana, pulsando desejos com os pares nas redes de comunicação. São potencializadas por dispositivos tecnológicos que, antes de tudo, é resultado do intercruzamento das relações humanas com as linguagens digitais, fazendo surgir verdadeiros espetáculos cenológicos de cultivo, partilha e transmissão de saberes e conhecimentos, criados e negociados por meio das estratégias de convívio dos/das jovens, exponencialmente vividas durante à pandemia da COVID-19, colocando em destaque, novos estilos e experiências de mediação das aprendizagens na/com as mudanças já sentidas, em curso. As mediações-lives fazem parte do conjunto das inovações sociais performáticas que emerge das intervenções cotidianas frente aos desafios do mundo para além da pandemia.

\section{Referências}

Bião, A. (2007). Um trajeto, muitos projetos. In: Artes do corpo e do espetáculo: questões de etnocenologia. Salvador: P\&A. [GS Search]

Carlson, M. (2010). Performance: uma introdução crítica. Belo Horizonte: Editora: UFMG.

Cepal. (2018). Comissão Econômica para a América Latina e o Caribe. Informe 2018. Latinobarómetro Corporación: Santiago de Chile.

CGI. (2019). TIC Domicílios 2018. Pesquisa sobre o uso das tecnologias de informação e comunicação nos domicílios brasileiros. São Paulo. Comitê Gestor da Internet no Brasil.

Di Felice, M. (2017). Net-ativismo e ecologia da ação em contextos reticulares. In: Di Felice, M.; Pereira, E.; Roza, E. (Orgs). Net-ativismo: redes digitais e novas práticas de participação. Campinas -SP: Papirus. [GS Search]

Galeffi, D. (2009). O rigor nas pesquisas qualitativas: uma abordagem fenomenológica em chave transdisciplinar. IN: MACEDO, Roberto Sidnei, GALEFFI, Dante; PIMENTEL, Álamo. Um rigor outro sobre a qualidade na pesquisa qualitativa: educação e ciências humanas. Salvador: EDUFBA.

Garfinkel, H. (1967). Studies in ethnomethodology. 2. ed. London: Routledge Press. Portuguese translation by Editora Vozes.

Goffman, E. (2011) A Representação do Eu na Vida Cotidiana. 14ª ed., Editora Vozes, Petrópolis.

Jenkins, H. (2008). Cultura da Convergência. São Paulo: Editora Aleph.

Johnson, S. (2003). Emergência: a vida integrada de formigas, cérebros, cidades e softwares. Rio de Janeiro: Jorge Zahar

Macedo, R. S. (2012). A etnopesquisa implicada. Brasília: Liber Livro.

Macedo, R. S.; Galeffi, D.; Pimentel, Á. (2009). Um rigor outro sobre a qualidade na pesquisa qualitativa: educação e ciências humanas. Salvador: EDUFBA.

Macedo, R.S. (2015) Pesquisar a Experiência: compreender/mediar saberes experienciais. Curitiba- PR: CRV.

Macedo, R.S (2010). Etnopesquisa crítica/Etnopesquisa-formação. Brasília: Líber Livro, 2010

Maffesoli, M. (2010). O tempo das tribos: o declínio do individualismo nas sociedades de massa. $4^{\circ}$ Ed. Rio de Janeiro: Forense.

Maffesoli, M. (2017). Net-ativismo: do mito tradicional à cibercultura pós-moderna. In: Di Felice, M.; Pereira, E.; Roza, E. (Orgs). Net-ativismo: redes digitais e novas práticas de participação. Campinas -SP: Papirus. 
Martín-Barbero, J. (2008). Dos meios às mediações: comunicação, cultura e hegemonia. Rio de Janeiro: UFRJ.

Martín-Barbero, J. (2018). A comunicação na educação. São Paulo: Contexto.

Podcast. México: Maffesoli. M. (2019). Tecnologías del imaginário. [Locução de]: Michel M. [S.I]. Docu.ibero 90.9 FM. Universidade Ibero Americana. Podcast. Disponível em: https://ibero909.fm/documentales-909-1/maffesoli-tecnologas-del-imaginario-narcicismo-ylas-kardashians. Acesso em: 20 de Julho. 2020.

Prensky, M. (2006). Don't Bother me, Mom, I'm Learning!: how computers and video games are preparing your kids for 21 st century success and how you can help! St. Paul: Paragon House Publishers.

Roza, E.; Melo, R. (2017). A experiência Net-ativista das vadias no Brasil. In: Di Felice, M.; Pereira, E.; Roza, E. (Orgs). Net-ativismo: redes digitais e novas práticas de participação. Campinas -SP: Papirus.

Santaella, L. (2019). Desafios humanos no contemporâneo. $1^{\circ}$ ed. São Paulo: Estação das Letras e Cores.

Santaella, L. (2019). Do pós-humano ao neo-humano: a sétima revolução comunicacional cognitiva do sapiens. In: XII Simpósio Nacional da ABCiber: devires da Cibercultura: políticas e prática. Porto Alegre.

Santaella, L. (2017). Política nas redes e nas ruas. In: Di Felice, M.; Pereira, E.; Roza, E. (Orgs). Net-ativismo: redes digitais e novas práticas de participação. Campinas -SP: Papirus.

Santos, E. (2020). \#livesdemaio... Educações em tempos de pandemia. Revista Docência e Cibercultura. Notícias Online. Disponível em: https://www.epublicacoes.uerj.br/index.php/re-doc/announcement/view/1109. Acesso em: 20 de Julho de 2020.

Santos, J. F.; Santos, V. S.; Nunes, A. K. F. (2019). Espaços de infoinclusão: o museu do amanhã enquanto agente educacional na cibercultura. In: Anais do II Encontro Regional Norte e Nordeste da ABCiber: redes educativas e os desafios atuais da cibercultura. [GS Search]

Santos, V. S. (2015) Jogos eletrônicos, cultura juvenil e socialidade: a aprendizagem social virtual mediada e suas influências para a educação. $1^{\circ}$. ed. Novas Edições Acadêmicas.

Santos, V. S.; Schneider, H. N. (2019). Culturas Juvenis e a Etnocenologia Virtual da Aprendizagem em Ambiências Híbridas e Multimodais de Interação. Educação Unisinos (Online)., v.23, p.1 - 17. doi: 10.4013/edu.2019.234.01 [GS Search]

Schechner, R. (2006) O que é performance?, em Performance studies: na introduccion, second edition. New York \& London: Routledge.

Schneider, H. N.; Santos, V. S.; Santos, J. F. (2020). Cultura Juvenil, Dependência Digital e Contingência. Rios Eletrônica (FASETE), v.23, p. 41 - 54. [GS Search]

Sibilia, P. (2018). Los cuerpos visibles en la contemporaneidad: de la purificación mediática a la explicitud artística. Kaypunku: Revista de Estudios Interdisciplinarios de Arte y Cultura, v. 4, p. 175-198. [GS Search]

Tapscott, D. (2010). A hora da geração digital: como os jovens que cresceram usando a internet estão mudando tudo, das empresas aos governos. (Tradução de Marcelo Lino). Rio de Janeiro: Agir Negócios 
Thadei, J. (2018). Mediação e educação na atualidade: um diálogo com formadores de professores. In: Bacich, L.; Moran, J. Metodologias Ativas para uma educação inovadora: uma abordagem teórico-prática. Porto Alegre: Penso. 